\title{
IMPROVING THE DURABILITY OF CULTIVATOR BLADES USING ONE-SIDED GAS-FLAME SURFACING
}

\section{Azamat Fayurshin}

Federal State Budgetary Educational Establishment of Higher Education "Bashkir State Agrarian University", Department of Technology of metals and repair of machines, Ufa, Russia

\section{Linar Islamov}

Federal State Budgetary Educational Establishment of Higher Education "Bashkir State Agrarian University", Department of Technology of metals and repair of machines, Ufa, Russia

\section{Ilnara Bagautdinova}

Federal State Budgetary Educational Establishment of Higher Education "Bashkir State Agrarian University", Department of Technology of Mechanics and Design of Machines, Ufa, Russia
Mars Farkhshatov

Federal State Budgetary Educational Establishment of Higher Education "Bashkir State Agrarian University", Department of Technology of metals and repair of machines, Ufa, Russia

\section{IInar Gaskarov}

Federal State Budgetary Educational Establishment of Higher Education "Bashkir State Agrarian University", Department of Technology of metals and repair of machines, Ufa, Russia

\section{Rinat Saifullin}

Federal State Budgetary

Educational Establishment of Higher Education "Bashkir State Agrarian University", Department of Technology of metals and repair of machines, Ufa, Russia

\section{Rivaz Masyagutov}

Federal State Budgetary Educational Establishment of Higher Education "Bashkir State Agrarian University", Department of Technology of metals and repair of machines, Ufa, Russia

Key words: protective blade cover, micro-structure, cultivator blades, increase of durability, one-sided gas-flame surfacing technology

\section{Cite article:}

Azamat, F., Mars, F., Rinat, S., Linar, I., Innar, G., Rivaz, M., \& IInara, B. [2021]. Design of highly redundant fault tolerant control for aircraft elevator system. Journal of Applied Engineering Science, 19(1), 57 - 67. DOI:10.5937/jaes0-27725

Online aceess of full paper is available at: www.engineeringscience.rs/browse-issues 


\title{
IMPROVING THE DURABILITY OF CULTIVATOR BLADES USING ONE-SIDED GAS-FLAME SURFACING
}

\author{
Azamat Fayurshin ${ }^{1 *}$, Mars Farkhshatov ${ }^{1}$, Rinat Saifullin', Linar Islamov', Ilnar Gaskarov', Rivaz \\ Masyagutov', Ilnara Bagautdinova ${ }^{2}$ \\ ${ }^{1}$ Federal State Budgetary Educational Establishment of Higher Education "Bashkir State Agrarian \\ University", Department of Technology of metals and repair of machines, Ufa, Russia \\ ${ }^{2}$ Federal State Budgetary Educational Establishment of Higher Education "Bashkir State Agrarian \\ University", Department of Technology of Mechanics and Design of Machines, Ufa, Russia
}

In agrarian production one of the most common technological operations is cutting of soil or plants. It makes up at least $70 \%$ of the total volume of mechanized works. The purpose of this study is to help maintain the agrotechnical parameters of the cultivator's blade by coating the blade with powder wear-resistant coatings using the one-sided gas-flame surfacing technology. The technology of strengthening the cultivator blade using one-sided gas-flame surfacing is applied. The technology of one-sided gas-flame surfacing guarantees an even reinforcing layer of the cultivator blade with a width of 10-12 $\mathrm{mm}$ and a layer thickness of $0.2 \mathrm{~mm}$. With the development of gasometric spraying methods it is possible to atomize various materials such as polymers, carbides, metals. These coatings withstand the impact of high thermal loads, shock-abrasive and chemically active environments. Therefore, the addition of chromium carbide powder PG-12N-02 has a positive effect on the properties of the coating. It increases the durability and wear resistance of the cultivator blades. A saw-tooth blade is formed. Comparison of application methods mentioned above shows that the quality of coatings expressed in the parameters: adhesions, porosity, oxidation levels remain at approximately the same level. However, a comparative analysis of foreign practice has shown that the method of gas-flame surfacing is more technological, more productivity, and the specific costs of the coating are reduced.

Key words: protective blade cover, micro-structure, cultivator blades, increase of durability, one-sided gas-flame surfacing technology

\section{INTRODUCTION}

It is known that the cultivator blade loses its agrotechnical parameters due mainly to abrasive and other types of wear. The material loses its colour. There is also breakdown due to metal fatigue, corrosion and cavitation destruction, liquid and gas erosion [1].

Abrasive wear and corrosion are the main types of wear on working bodies of tillage machines. For example, researchers $[2,3,4,5]$ found that the working bodies of tillage machines by the nature of their functions are directly related to materials that can cause abrasive wear. In addition, abrasive wear due to the localization and high concentration of contact stresses can cause intense destruction of the surface layer occurs, suppressing even with a small number of abrasive particles, other types of wear.

It is possible to increase the durability of the cultivator blade by adding alloying components to the chemical composition of the reinforcing material to form structures that counteract the processes of wear [1,4]. The ability to increase resistance to wear processes allows to weld seam wear-resistant coatings on the friction surface of parts, which will reduce structural transformations that occur under mechanical and thermal influences on the surface of the cultivator blade [6]. Thus, the variety of existing technologies and methods to improve the durability of cultivator blades based on the factors of chemical, thermal and mechanical effects, which in turn allow the working bodies to comply with agrotechnical parameters [7, 8, 9, 10].

Geothermal coating is one of the ways to strengthen the working bodies of tillage machines and create a surface layer that meets the increased operational requirements. A much simpler, cheaper and mobile method of application is one - way gas-flame weld seaming of powders. The advantages of this method in comparison with others such as plasma spraying, electric arc metallization, etc., is performance efficiency, which provides a high coefficient of material use, as well as minimal burnout of alloying elements [2, 11, 12].

The technology of one-sided gas-flame surfacing allows obtaining wear-resistant coatings on the functional surface of the cultivator blade. The use of fused surfaces made of self-fluxing powders makes it possible to achieve high temperature resistance and chemical resistance in many environments $[13,14,15]$.

The purpose of this study is to prove theoretically and experimentally confirm the optimal parameters for the geometries of blades and toes of cultivator blades, determining their strength, wear resistance and self-sharpening (sawing).

\section{MATERIALS AND METHODS}

It is good enough to weld a very thin layer (less than 1 $\mathrm{mm}$ ) to ensure the working efficiency of the cultivator's blade working surface. In this case, the desired chem- 
ical composition of the surfaced metal can be obtained only with a very small penetration in the base metal. Of the existing methods, one-sided gas-flame weld seam meets these requirements to some extent $[16,17]$.

For a high-quality surfacing of filler powder and reliable operation of the burner, it is necessary to ensure the correct selection of equipment and the mode of one-way gas-flame surfacing.

The existing Euro JETX-8 burner (Fig. 1) is designed for surfacing of metal powder with a layer from $0.1 \mathrm{~mm}$ to several millimetres on both large and small parts. This particular burner is equipped with three types of nozzles: №1, №2, №3. Combustible mixture parameters during weld seam of powder are set as follows: acetylene- 0.5 bar, oxygen-2 bar.

During surface washing it is necessary to avoid oxidation. Thus, composite material and the method of metal powder application should provide a minimum porosity. Granulation of the powder composition should be optimally loose, something that. All of the conditions mentioned above guarantee the necessary value of bonding force of the applied layer with the surface of the base metal in the process of surface washing.

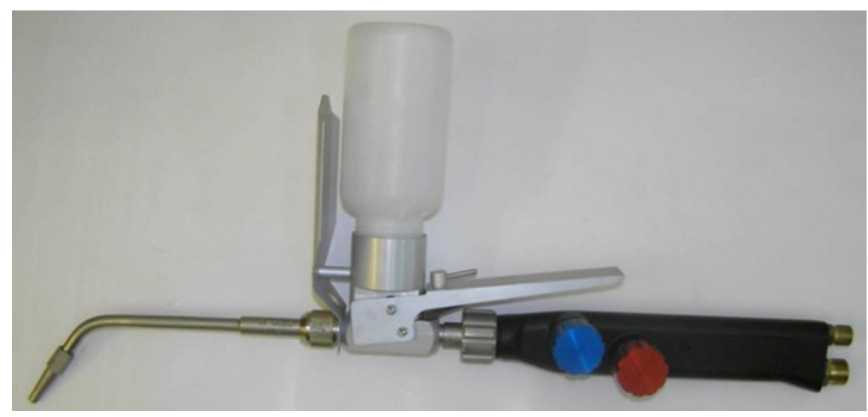

Figure 1: EURO JET XS-8 burner

Thus, powder materials are made based on two or more components. In our case, carbide of refractory metals: one of the constituent elements of the powder serves as a binder, and the other is a product of a molded mixture of powders. The advantages of refractory carbides are: high melting point, increased hardness and wear resistance, resistance to acids and alkalis. Physical properties of some refractory metal carbide are presented in Table 1 [18].

When making a composite powder material it is necessary to consider such factors as: the quantitative and granulometric composition of the powder, the melting point of the powder composition and mechanical properties. All of the above affects the strength of the coating during the technological process of one-sided gas-flame surfacing $[19,20]$.
During building of metal powder composite on the surface of the cultivator blades technological parameters also have a significant impact on the strength of the layer. These parameters include: the nature of material feed; deformation of the constituent particles; the nature of solid particle placement in the surface layer.

The coatings were applied with EURO JET XS-8 burner using propane as a combustible gas and oxygen. The temperature of the torch is approximately $2400{ }^{\circ} \mathrm{C}$. The particle velocity at the outlet is about $200 \mathrm{~m} / \mathrm{s}$. The welded on composite powder material was made from PG-12N-02 metal powder (Table 2) with chromium carbide admixture in the weight ratio, wt \%: chrome carbide grain-PG-12N-02 powder: 1:1, 1.2:1, 1.6:1. Applied chromium carbide powders with granularity $20 . .63,40 \ldots 100$, $80 . .160,100 \ldots 280$ micrometres.

Thus, in the structure of the composite powder material, the average grain diameter was 90 microns; the maximum diameter is 160 microns and the minimum-45 microns. The thickness of the welded-on layer of the cultivator blade's surface is $0.4-0.6 \mathrm{~mm}$. The mass ratio of carbide grains in a bundle averaged $30 \%[18,15]$.

On the surface of cultivator blades the welded-on composite powder came in the form of small liquid melted droplets, which hitch onto metals (the base), deform and while fixing in place, piled up on top of each other forming layered coverage. The microstructure of the strengthened coating of the cultivator blade, obtained by one-sided gas-flame weld-seam, is complex and has multiple phases. As a result of this there is a need to study the microstructure of the layer.

\section{Research methods used to strengthen the cultivator blade layer}

To determine the bond strength of the coating with a thickness $\leq 0,3 \ldots 0.4 \mathrm{~mm}$ including the base metal, a method involving strength tests on cutting of fixed coating platforms, proposed by the author [16] and on the re-

Table 1. Physical and mechanical properties of refractory metal carbides

\begin{tabular}{|c|c|c|c|}
\hline Indicators & $\mathrm{TiC}$ & $\mathrm{Cr}_{3} \mathrm{C}_{2}$ & $\mathrm{WC}$ \\
\hline Specific weight, $\mathrm{kN} / \mathrm{m}^{3}$ & 47 & 56 & 156 \\
\hline Melting point, ${ }^{\circ} \mathrm{C}$ & 3140 & 1895 & 2870 \\
\hline Hardness, HRA & $92 \ldots 93$ & 85 & 92 \\
\hline Microhardness, PA & 0.032 & 0.013 & 0.024 \\
\hline
\end{tabular}

Table 2. Powder chemical composition and coating hardness

\begin{tabular}{|c|c|c|c|c|c|c|c|}
\hline \multirow{2}{*}{ Powder brand } & \multicolumn{5}{|c|}{ Nominal chemical composition, \% Core components } & \multirow{2}{*}{ Coating hardness HRC } \\
\cline { 2 - 7 } & $\mathrm{Ni}$ & $\mathrm{Cr}$ & $\mathrm{B}$ & $\mathrm{Si}$ & $\mathrm{Fe}$ & $\mathrm{C}$ & \\
\hline PG-12N-02 & base & $10 \ldots 16$ & $2.0 \ldots 4.0$ & $3.0 \ldots 5.0$ & $3 \ldots 6$ & $0.4 \ldots 0.8$ & $52 \ldots 56$ \\
\hline
\end{tabular}


sistance to an impact cut was chosen [18]. This method of strength tests consisted of (Fig. 2): a pre-cut strip of asbestos sheet was placed on the sample, maintaining a $1 \mathrm{~mm}$ width the composite material was welded-on using a gas-flame burner.

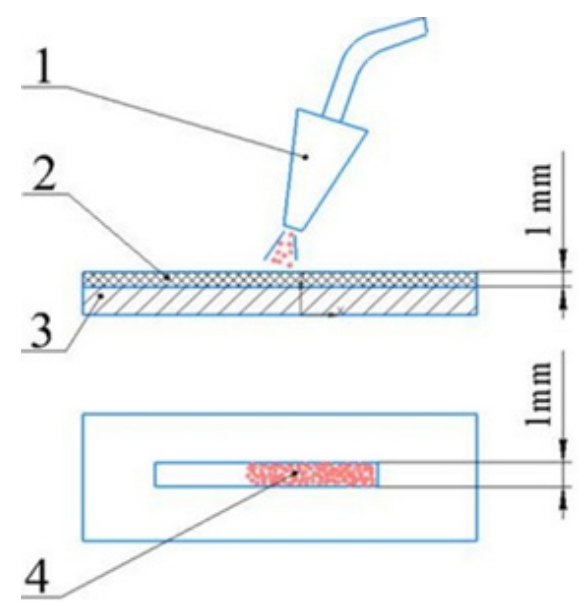

Figure 2: Obtaining fixed platforms:

1-burner, 2-asbestos sheet, 3-sample, 4-applied layer

After the welded-on strip of the composite coating was subjected to milling, as a result of which the required platforms of $1 \times 1 \mathrm{~mm}$ were left on the surface of the sample.

The next stage was aimed at testing the strength of platforms obtained by one-sided gas-flame surfacing of powder material to the plates, which was carried out using the mandrel shown in Fig. 3, 4. The experiment consisted of the next steps: in housing 1 carbide plates 2 were fixed in place, between which we install sample 4 with a relative gap in the thickness of the sample. At the same time, it was necessary a tight fit of the sample to the plates along the cut plane, using a fixing platform 5 .

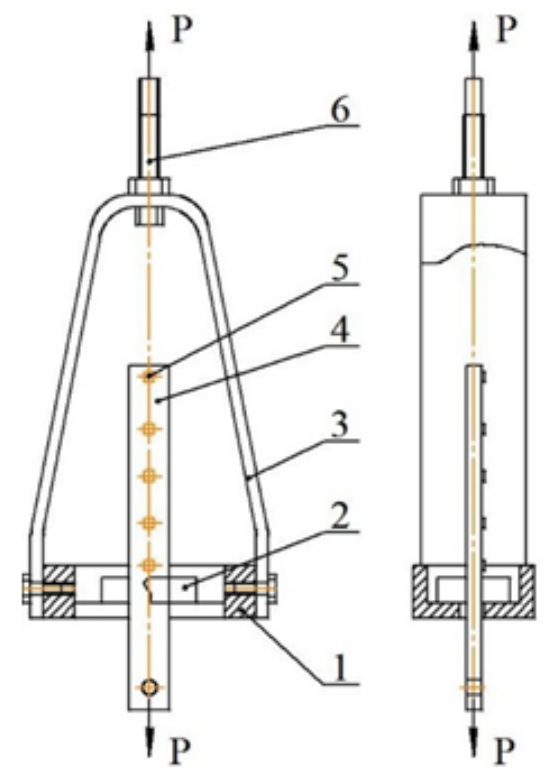

Figure 3: Test plane for cutting of fixed platforms: 1-housing, 2-carbide plates, 3-clamp, 4-sample, 5-fixed platform, 6-rod

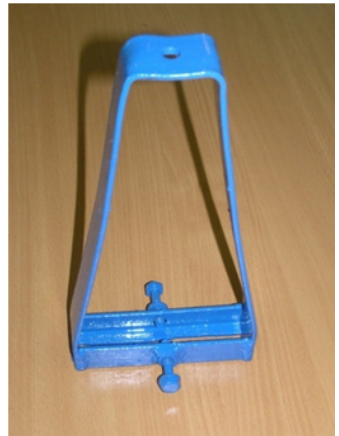

Figure 4: Fixture for cut testing of fixed platforms

If there is a need for a more precise adjustment of this gap to the thickness of the sample, it is removed with the help of specially selected spacers. Next, the fixture is installed on the machine for mechanical tests, clamped by rod 6 , fixed on clamp 3 , fixed to housing 1 , and the lower end of sample 4 in its grips. On the installed fixture force $P$ is applied and the fixed platform is cut off in the zone of its connection with a sample. After cutting off one platform under the carbide plates of the fixture next platform is installed. These actions are similarly repeated.

According to the calculation formula (1), the bonding strength of the reinforcing layer $\tau$ with the base metal was determined:

$\tau=\frac{P_{a v}}{F}$

where $P_{a v}$ is the shear load;

$F$ is the connection area.

Next the micro-hardness of the hardened surface of the cultivator blade was measured using the PMT-3 micro-hardness tester in accordance with the regulation document State All-Union standard 9450-76 "Micro-hardness testing method with indentation of a diamond pyramid" [18].

Thus, the load on the diamond pyramid during measurements was $1,962 \mathrm{~N}(200 \mathrm{~g})$. According to the diagram presented on Figure 5, measurements were made to assess the distribution of micro-hardness along the depth and length of the cultivator blade.

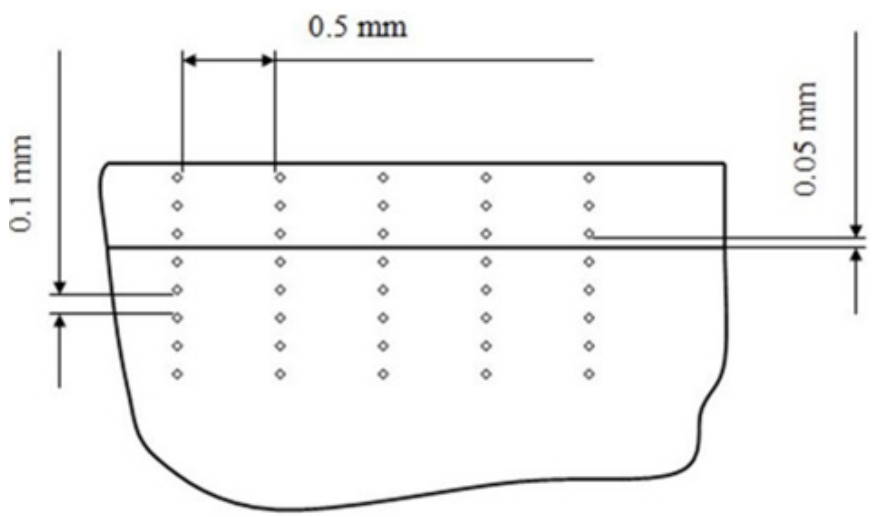

Figure 5: Diagram of micro-hardness measurement of the strengthened and restored surface of a cultivator blade 
Samples of the studied surfaces were photographed and transferred to a PC with the help of an optical microscope "Neophot".

Hardness measurements were made using TK-2 State All-Union standard 13407-67 measuring device.

One of the important indicators in the research is the energy-dispersive analysis. This method allows analyzing the processes occurring between metals in liquid and solid state. The analysis was made on an electronic scanning microscope JSM-840 [21, 12, 22].

The production of micro-sections began with the obtainment of cross-cuts of the cultivator blades, surfaced with a layer of composite powder material using this technology. Having previously prepared aluminium rings which are no more than $30 \mathrm{~mm}$ in diameter and no more than $3 . .4 \mathrm{~mm}$ thick, the prepared cross-cut sections were placed and the voids were filled with Wood's alloy. Next, the obtained micro-sections were polished on a polishing table using polishing pastes GOI No. 2 (TU 6-18-36). After this process the micro-sections obtain a smooth mirror-like surface.

To evaluate the wear resistance of the cultivator's blade, the values of wear rate in the sections most exposed to wear were taken. This assessment allows determining the resource that implements the study of wear resistance for various elements of cultivator blades. It also allows us to diagnose agrotechnical requirements for quality of soil treatment and cutting of weeds.

A calculation formula (2) was used to determine the wear rate of the cultivator's blade wear resistance

$V=\frac{\left(B_{1}-B_{i+1}\right)}{\left(N_{i+1}-N_{i}\right)}, m m / h a$

where $B_{i}, B_{i+1}$-blade width (conditional nose-piece length, blade width) for $i$ and $i+1$ measurements, $\mathrm{mm}$;

$N_{i+1}, N_{\mathrm{i}}$ - operating time of the blade at measurement moments $i$ and $i+1$, ha.

Comparison of serial cultivator blades with experimental cultivator blades made it possible to determine the final estimate of relative wear resistance coefficient, equal to the ratio of wear rates of serial and experimental paws.

However, the cultivator blade has a variable blade width, which makes it difficult to measure the blade width with a universal measuring tool. The formation of measuring bases in the form of cuts on the working surface of the blade also complicates the accuracy of measurement due to the fact that it does not allow to measure by standard to the blade. Taking into account everything mentioned above, a relative width equal to the distance from the blade to the artificial measuring base in the form of the front surface of a special template was adopted. It was applied to the cultivator blade from above and pressed by a clamp, was adopted.

According to the diagram (Fig. 6), a template made of duralumin sheet is attached to the upper surface of the cultivator blade. Linear measurements were made us-

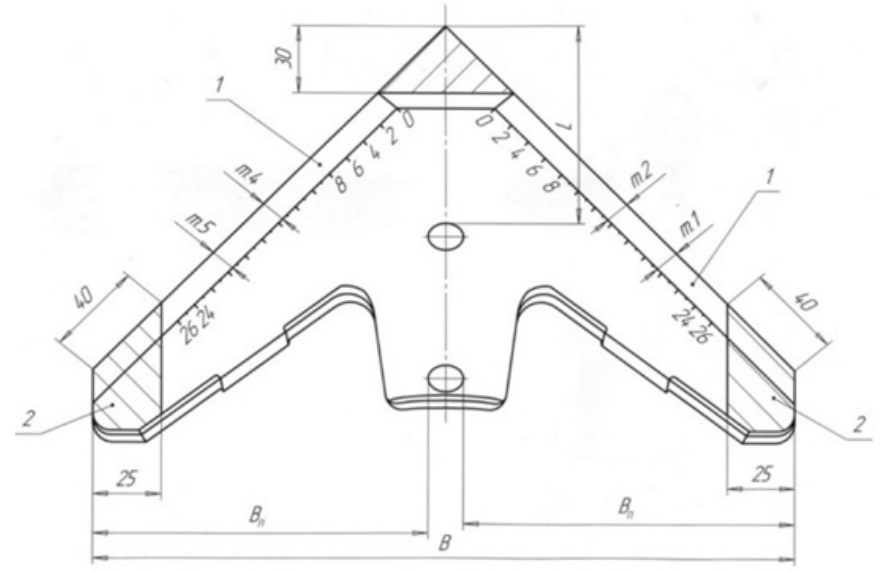

Figure 6: Measurement zones of linear wear of A-hoe blades: 1-blade zone, 2-wing end zone

ing measuring Vernier beam compass of SHC-125 type, also having a depth gauge with a division value of 0.02 $\mathrm{mm}$. From an end face of the template's surface cuts were made. Depth-gauge of the beam compass was inserted into these cuts.

In accordance with the normative document State Allunion standard 23.2.164-87 "blades and stands of cultivators" 21 different sizes of universal blades are provided. For Fast-moving Field Cultivator (FFC)-4 size 3 blades are used. They have a width of $270 \mathrm{~mm}$, a metal thickness of $5 \mathrm{~mm}$, as well as a typical size 5 (width is $330 \mathrm{~mm}$, the thickness of the metal is equal to $6 \mathrm{~mm}$ ). The following cultivator blade angles are provided for the above dimensions: The angle of nose-piece crumbling is of $26^{\circ} 40$; the cone angle is $2 \gamma^{\prime}$; the angle of wings of the blade crumbling is $28^{\circ}$, providing the necessary loosening of soil without turning the formation; the radius is $230 \pm 4(\mathrm{~mm})$.

To determine the ultimate state of the cultivator blade, the following criteria were taken into account: wear across the width of the blade is equal to $50 \mathrm{~mm}$, excluding mutual overlap on the treated zone with the first and the second rows of blades; wear of the nose-piece reaches $30 \mathrm{~mm}$; wear of the blades across the width is equal to $15 \mathrm{~mm}$; wear of the shank, excluding the possibility of mounting bolt installation; bent, fracture of wings.

The first three of the mentioned above criteria are determined by the width and type of welded-on hard alloy, in the presence of which the process of self-sharpening should be carried out.

In operation, cultivator blades with a width of $270 \mathrm{~mm}$ were installed on the front row of FFC-4 cultivator. Blades with a width of $330 \mathrm{~mm}$ were installed on the back row. Cultivator FFC-4 was aggregated using tractors the traction class of which was 1.4 (1 unit), traction class 3 (1 unit), traction class 4 (1 unit) blades, which have exhausted their resource, were replaced by serial blades. 


\section{Modelling of cultivator blades}

To clarify the experimental data, a three-dimensional model of an existing cultivator blade design was developed and implemented in the Flow Vision software package. Model of the cultivator blade, allows analyzing the distribution of pressure on different surface areas of the blade during its operation. Based on Figure 7, we can say that the maximum pressure does appear on the blades, so it is advisable to strengthen the surface of the cultivator blade at a pressure of more than 3000 PA. This allows increasing the durability of the blade, and ensures their self-sharpening when aggregating [23].

The developed model provides an opportunity to detect zones of maximum wear at the design stage for the construction of replaceable (wear-resistant) parts or to obtain such parameters of working bodies, at which it is possible to minimize the negative impact of soil on them.
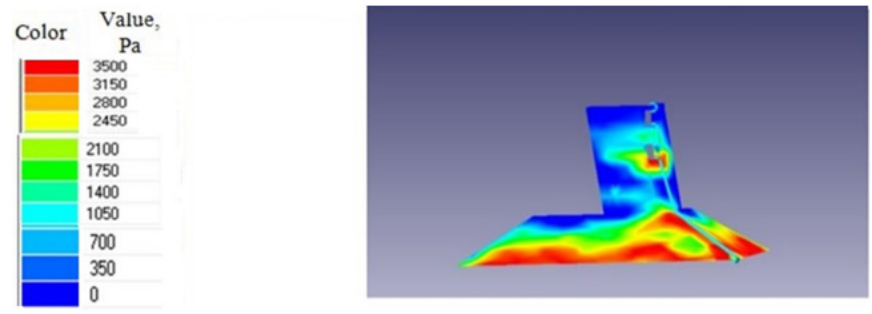

Figure 7: Pressure distribution at different areas of the surface cultivator blades

\section{Mathematical calculation}

The number of cultivator blades should ensure accuracy during the testing. It should be noted that the distribution of wear complies with the normal distributive law. Thus, the variation coefficient $v$ during testing of wear resistance according to research results is [22] 0.3...0.4. The confidence coefficient $a^{*}$ which values are within the range of $0.80 \ldots 0.95$ is considered adequate for testing agricultural machinery. Therefore, the number of blades $n$ is determined using the expression [20]

$\frac{t_{a}{ }^{*}}{\sqrt{n}}=\frac{\delta}{v}$ where $t^{*}$ is the Student's coefficient;

$\delta$ is the relative error, usually $\delta=0,10 \ldots 0,20$.

When in expression $3 \delta=0.20$ and $v=0.30$, we determine that

$\frac{t_{a}{ }^{*}}{\sqrt{n}}=0.667$

When $a^{*}=0.80$, we find that $n=5$ using Student's coefficient table.

Thus, taking into account all of the mentioned design parameters, it can be said that the installation of five experimental and five serial blades on the cultivator will provide sufficient reliability of the results.

The next step was the assessment of suitability for the use of experimental blades for cutting weeds according to the normative document State All-union standard 33687-2015 "Machines and tools for surface tillage. Testing methods". Thus, weeds clipping is determined by the ratio of the number of clipped plants to the number of weeds available before processing in the discount area [3, 24].

The studies were carried out as follows: discount areas on which blockage of a site was defined before processing were marked using sticks. The account of weed clipping was done with quadruple repetition: two repetitions forward and two backward. Then, the FFC-4 cultivator was equipped with all available quantity of one-type experimental blades. After that surface treatment of soil at a certain rutting length was made.

As a result, the number of experimental blades did not match by variants. Thus, the length of the rut in each case was chosen based on the condition of ensuring the treated area $\mathrm{F}=2 \mathrm{~m}^{2}$. This area size was chosen on the basis of State All-union standard 33687-2015, in which the clipping account is determined on areas of rut with a length of $0.5 \mathrm{~m}$ and a width $(\mathrm{V})$, which is equal to the width of the tool. For FFC-4: V=4m. Thus, the accounting area for the FFC-4 cultivator is $2 \mathrm{~m}^{2}$. Calculated and accepted lengths of the ruts when determining clipping are given in Table 3.

Table 3: Calculated and accepted lengths of furrow during determination of pruning of weeds

\begin{tabular}{|c|c|c|c|c|}
\hline Blade variant No. & $\begin{array}{c}\text { Number of blades } \\
(\text { width, } \mathrm{mm})\end{array}$ & $\begin{array}{c}\text { The total blade operat- } \\
\text { ing width } \mathrm{m}\end{array}$ & $\begin{array}{c}\text { Estimated } \\
\text { length of the section, } \mathrm{m}\end{array}$ & $\begin{array}{c}\text { Accepted length } \\
\text { of section, } \mathrm{m}\end{array}$ \\
\hline 1 & $2(270)$ & 0.52 & 3.85 & 4 \\
\hline 2 & $2(270)$ & 0.52 & 3.85 & 4 \\
\hline 3 & $5(270)$ & 1.27 & 1.57 & 1.5 \\
\hline 4 & $6(270)$ & 1.385 & 2.41 & 2.5 \\
\hline 5 & $3(330)$ & 0.83 & 2.41 & 2.5 \\
\hline 6 & $3(330)$ & 0.83 & 1.04 & 1 \\
\hline 7 & $8(330)$ & 1.915 & 1.04 & 1 \\
\hline 8
\end{tabular}


Qualitative parameters of the cultivator blades were determined at different sharpening angles and different thickness of the blade [25]. For example, on the grinding and sharpening machine from the upper front side of the blade it was sharpened at angles 11, 18, 23, 43o, while the thickness of the blade when sharpening was brought to $0.15-0.20 \mathrm{~mm}$. Thickness measurement were carried out by obtaining blade impressions on lead plates $(5 \times 30 \times 300 \mathrm{~mm})$.

To obtain the natural shape of the blade with a required thickness, the blades of the cultivator were previously subjected to wear in the field.

\section{RESULTS AND DISCUSSION}

Experimental and theoretical studies have made it possible to determine the optimal ratio of the number of carbide grains and links.

In order to study the thickness of the formed layer depending on the size of the granules in the experimental powder composition, an experiment was conducted on its granulometric composition (Fig. 8): the size of 259 grains of chromium carbides was determined using a microscope. Also, studied series were grouped into 7 classes and for the normal rule of distribution of the kind according to the criterion K. Pearson $\chi^{2}$.

$$
f(d)=0,019941 e^{-\left(\frac{d-82,23}{28,293}\right)^{2}}
$$
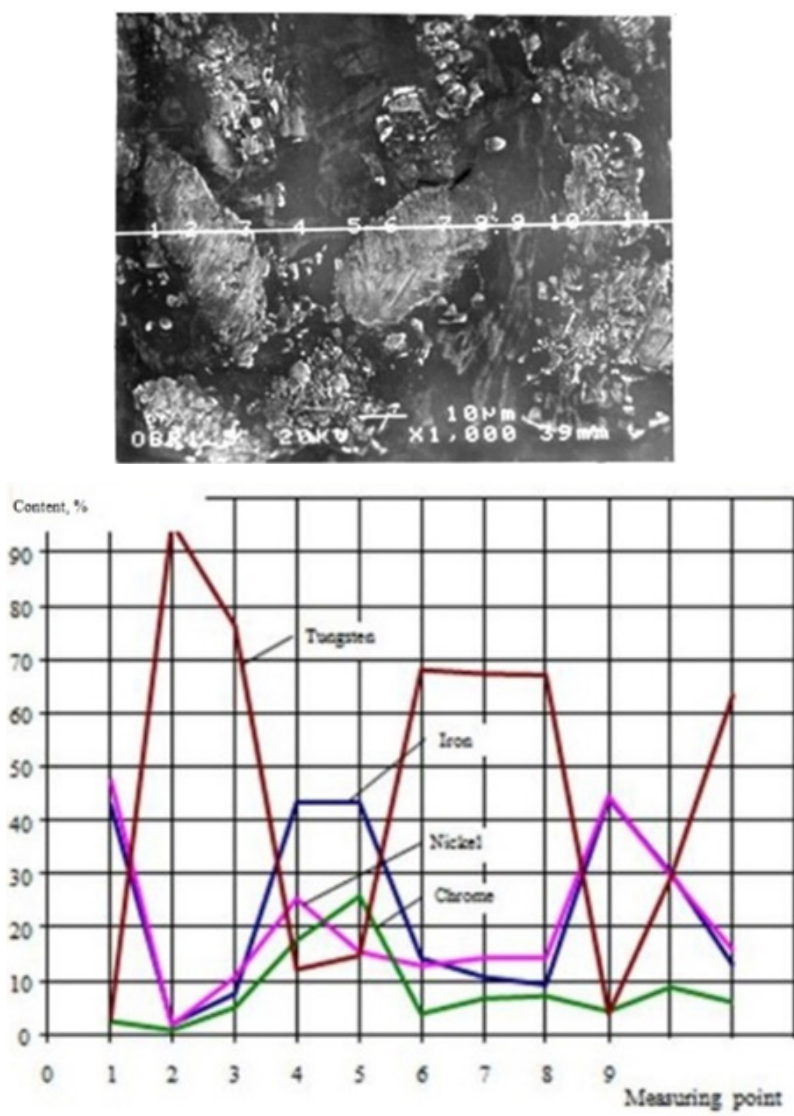

Figure 8: Microstructure and distribution graph of main elements of the applied layer
According to the pictures of the microstructure of the hardened layer, which are presented in Fig. 8, it is possible to analyze the water affinity of the binder grains of metal carbides. At the boundary of the binder layers with the base metal of the blade, there is a clear boundary of the layers between the applied layer and the base metal. This makes it possible to obtain a fixed thickness of the blade. There are no pores, cracks and other defects on the hardened layer, which indicates the quality of the applied wear-resistant layer [18, 26, 5]. Distribution graph of the applied layer main elements shows that the weight ratio of the composite powder's components material changes in different weight ratios. A graph makes it possible to determine the optimal weight ratio of the composite powder material.

When the composite powder is welded on to the surface of the base metal, gas adsorption, oxidation and layering of small fractions of the material and its oxides occur. The coating is formed by successive stacking of many deforming particles in the atmosphere, which in turn lead to the appearance of micro-voids filled with gas.

Further, gases are released dissolved in melted particles, resulting in high values of roughness on the reinforced coating. This leads to extremely rapid spreading and crystallization of particles in the zone of contact with the surface of previously welded on particles, thus leaving defects in the cavities.

When adding PG-12H-02 chromium carbide to the powder the coating microstructure becomes more heterogeneous, but the number of pores is significantly reduced. This is caused by high activation energy of chromium particles. The structure of the strengthened layer is non-homogeneous. This is caused by different cooling conditions and heat transfer of the layers during the surfacing process. Unevenly distributed carbides on the plane of the cuts characterize the generated forms of the self-sharpening saw-tooth blade teeth (Fig. 9, 10).

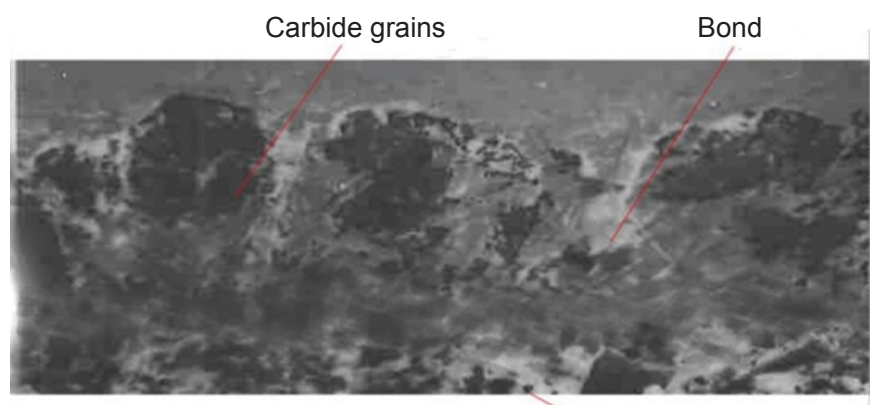

Base material

Figure 9: Microstructure of the applied layer

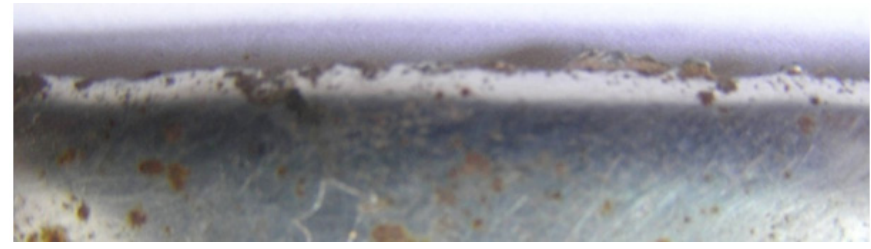

Figure 10: Self-sharpening cultivator blade saw-tooth blade tooth shapes 
Strengthened working bodies with one-sided gas-flame surfacing were subjected to operational tests. Table 5 shows the characteristics of the cultivator blades prepared for operational tests.

Next, operational tests of strengthened experimental and serial blades were carried out in soils of the Republic of Bashkortostan (black soil, medium loamy, loamy; soil moisture during surface tillage at different time periods varied within $15 \ldots 25 \%)$. Further, experimental and serial blades were subjected to measurements of geometric parameters, the results of which are given in Tables 6 and 7.

Analyzing table 6 , we can say that with increase in operating time of the cultivator's blade, the dynamics of wear of experimental and serial blades also increases.

Table 5: Characteristics of the blades which have been prepared for operational tests

\begin{tabular}{|c|c|c|c|c|c|}
\hline $\begin{array}{c}\text { No. of } \\
\text { variant }\end{array}$ & Name & Quantity & $\begin{array}{c}\text { Sharpening } \\
\text { angle, }\end{array}$ & $\begin{array}{c}\text { Layer width, } \\
\mathrm{mm}\end{array}$ & $\begin{array}{c}\text { Layer thickness, } \\
\mathrm{mm}\end{array}$ \\
\hline 1 & $\begin{array}{c}\text { Hand-made electric arc surfacing of blades on } \\
\text { the bottom using "sormayt-1" (serial) alloy }\end{array}$ & 2 & 23 & $10 \pm 2$ & $3 \pm 0.5$ \\
\hline 2 & $\begin{array}{c}\text { Induction surfacing of the blade from the } \\
\text { bottom alloy PS-14-60 (serial) }\end{array}$ & 2 & 23 & $10 \pm 2$ & $0.6 \pm 0.05$ \\
\hline 3 & $\begin{array}{c}\text { Gas-flame surfacing of the blade from the } \\
\text { bottom using PG-12N-02 (serial) alloy }\end{array}$ & 5 & 23 & $10 \pm 2$ & $0.5 \pm 0.05$ \\
\hline 4 & $\begin{array}{c}\text { Gas-flame spraying with subsequent weld on of } \\
\text { the CP (experimental) }\end{array}$ & 6 & 23 & $10 \pm 2$ & $0.3 \pm 0.05$ \\
\hline 5 & $\begin{array}{c}\text { Hand-made electric arc surfacing of blades on } \\
\text { the bottom using "sormayt-1" alloy(serial) }\end{array}$ & 3 & 23 & $10 \pm 2$ & $3 \pm 0.5$ \\
\hline 6 & $\begin{array}{c}\text { Induction surfacing of the blade from the } \\
\text { bottom alloy PS-14-60 (serial) }\end{array}$ & 3 & 23 & $10 \pm 2$ & $0.6 \pm 0.05$ \\
\hline 7 & $\begin{array}{c}\text { Gas-flame surfacing of the blade from the } \\
\text { bottom using PG-12N-02 alloy (serial) }\end{array}$ & 8 & 23 & $10 \pm 2$ & $0.5 \pm 0.05$ \\
\hline 8 & $\begin{array}{c}\text { Gas-flame spraying with subsequent CP } \\
\text { surfacing (experimental) }\end{array}$ & 8 & 23 & $10 \pm 2$ & $0.3 \pm 0.05$ \\
\hline
\end{tabular}

Table 6: Dynamics of wear for experimental and serial blades

\begin{tabular}{|c|c|c|c|c|c|c|c|c|c|c|}
\hline \multirow{2}{*}{ No } & \multicolumn{10}{|c|}{ Operating time, ha } \\
\cline { 2 - 12 } & 5 & 10 & 15 & 20 & 25 & 30 & 35 & 40 & 45 & 50 \\
\hline \multicolumn{10}{|c|}{ Wear, mm } \\
\hline 1 & 0.623 & 2.032 & 3.333 & 4.815 & 6.147 & 7.451 & 8.932 & 10.277 & 11.609 & 13.555 \\
\hline 2 & 0.608 & 1.343 & 2.154 & 2.882 & 3.845 & 4.971 & 5.879 & 7.067 & 8.647 & 10.442 \\
\hline 3 & 0.145 & 0.734 & 1.209 & 1.631 & 2.037 & 2.659 & 3.546 & 4.467 & 5.368 & 6.664 \\
\hline 4 & 0.103 & 0.432 & 0.651 & 0.987 & 1.357 & 1.816 & 2.379 & 3.268 & 4.068 & 5.029 \\
\hline 5 & 0.378 & 1.347 & 2.245 & 3.496 & 4.737 & 6.148 & 7.389 & 9.275 & 11.166 & 13.297 \\
\hline 6 & 0.338 & 0.865 & 1.485 & 2.196 & 3.019 & 3.951 & 4.843 & 5.916 & 7.276 & 9.397 \\
\hline 7 & 0.108 & 0.549 & 0.896 & 1.428 & 2.102 & 2.634 & 3.134 & 3.969 & 4.847 & 5.974 \\
\hline 8 & 0.096 & 0.504 & 0.719 & 1.063 & 1.375 & 1.776 & 2.192 & 2.869 & 3.542 & 4.559 \\
\hline
\end{tabular}


According to the obtained values in Table 7, we can also say that the dynamics of nose-piece wear of experimental and serial blades increases as well with the growth of operating time.

Analyzing Tables 8, 9 we can say that the blades which have been strengthened using methods 1-8, set the operating time to their limit state for a $10 \mathrm{~mm}$ (the width of the hardened layer) blade, and for the nose-piece $30 \mathrm{~mm}$. This is confirmed in turn from the linear wear regression equations.

So, for example, when calculating economic efficiency, it is necessary to take into account the limiting state of the blade of the paws in their thickness, not exceeding 0.4 $\mathrm{mm}$ or in the radius of curvature of the blade.

Comparative analysis of the data in Tables 8, 9 shows that after the operational testing of a serial blade operating time on the thickness of the blade reaches the limit state at values of $16-20$ ha/blade, which causes a need for additional sharpening of the blade. The value of the blade thickness and the operating time of the final condition of the experimental blades did not exceed the limit value, and self-sharpening was ensured during the entire period of operational tests.

Table 7: Dynamics of wear for nose-pieces of experimental and serial paws

\begin{tabular}{|c|c|c|c|c|c|c|c|c|c|c|}
\hline \multirow{2}{*}{ No } & \multicolumn{10}{|c|}{ Operating time, ha } \\
\cline { 2 - 12 } & 5 & 10 & 15 & 20 & 25 & 30 & 35 & 40 & 45 & 50 \\
\hline \multicolumn{10}{|c|}{ Wear, mm } \\
\hline 1 & 1.243 & 5.02 & 9.342 & 14.573 & 19.98 & 24.56 & - & - & - & - \\
\hline 2 & 0.902 & 2.564 & 5.424 & 8.471 & 12.32 & 14.315 & 17.827 & 22.279 & 26.03 & 28.79 \\
\hline 3 & 0.145 & 1.251 & 2.776 & 5.283 & 7.35 & 10.03 & 12.678 & 15.711 & 19.562 & 23.715 \\
\hline 4 & 0.125 & 0.897 & 1.691 & 2.97 & 4.13 & 5.807 & 7.816 & 10.19 & 12.453 & 14.817 \\
\hline 5 & 1.34 & 3.747 & 8.892 & 12.853 & 16.398 & 21.804 & 26.351 & 29.954 & - & - \\
\hline 6 & 0.87 & 1.765 & 4.298 & 6.539 & 9.476 & 12.609 & 15.737 & 18.543 & 22.445 & 25.896 \\
\hline 7 & 0.202 & 0.842 & 1.867 & 3.518 & 5.564 & 7.694 & 10.566 & 13.912 & 15.763 & 18.794 \\
\hline 8 & 0.195 & 0.604 & 1.437 & 1.961 & 3.965 & 4.867 & 6.549 & 8.806 & 10.993 & 11.69 \\
\hline
\end{tabular}

Table 8: Operating of the tested blades to the limit state on linear wear

\begin{tabular}{|c|c|c|c|c|c|c|c|c|}
\hline \multirow{2}{*}{ Control area } & \multicolumn{7}{|c|}{ Methods of strengthening } \\
\cline { 2 - 9 } & 1 & 2 & 3 & 4 & 5 & 6 & 7 & 8 \\
\cline { 2 - 8 } & \multicolumn{6}{|c|}{ Operating time to the limit state, ha / blade } \\
\hline Blade & 38 & 49 & 64.3 & 71.6 & 42 & 53 & 71.25 & 79.8 \\
\hline Nose-piece & 33 & 50 & 59.6 & 72.3 & 39 & 54.2 & 63.3 & 79.8 \\
\hline
\end{tabular}

Table 9: Operating of the tested blades to the limit state on the thickness of the blade

\begin{tabular}{|c|c|c|c|c|c|c|c|c|}
\hline \multirow{3}{*}{ Control area } & \multicolumn{7}{|c|}{ Methods of strengthening } \\
\cline { 2 - 9 } & 1 & 2 & 3 & 4 & 5 & 6 & 7 & 8 \\
\cline { 2 - 9 } & \multicolumn{7}{|c|}{ Operating time to the limit state, ha / blade } \\
\hline Blade & 18.6 & 22 & 25.3 & 71.6 & 20.5 & 23 & 27.7 & 79.8 \\
\hline Nose-piece & 16.3 & 19.1 & 19.6 & 72.3 & 17.7 & 19.1 & 20.4 & 79.8 \\
\hline
\end{tabular}


Measurements of linear wear of cultivator blades and their results are listed in Tables 6,7 and presented in Fig. 11-14.

Comparative analysis of Fig. 11-14 shows that the histograms $f^{x}(u)$ constructed on operational data of serial and experimental cultivator blades for the moments of operating time of cultivator blades of $10,20,30,40$ ha allow us to define statistics of wear of cultivator blades. During calculations statistical characteristics of the amount of cultivator blade wear were reduced to the distribution rows. The obtained histograms show that the intensity of wear of nose-pieces and blades of experimental and serial blades rises with the increase in operating time. This is associated with dulling of the blade and an increase in pressure on the cultivator blades.

The data obtained during the experiments allowed studying the agrotechnical parameters of the cultivator blade, which were determined by coating the blade with powder wear-resistant coatings using one-sided gas-flame surfacing technology. The studies have shown that the most

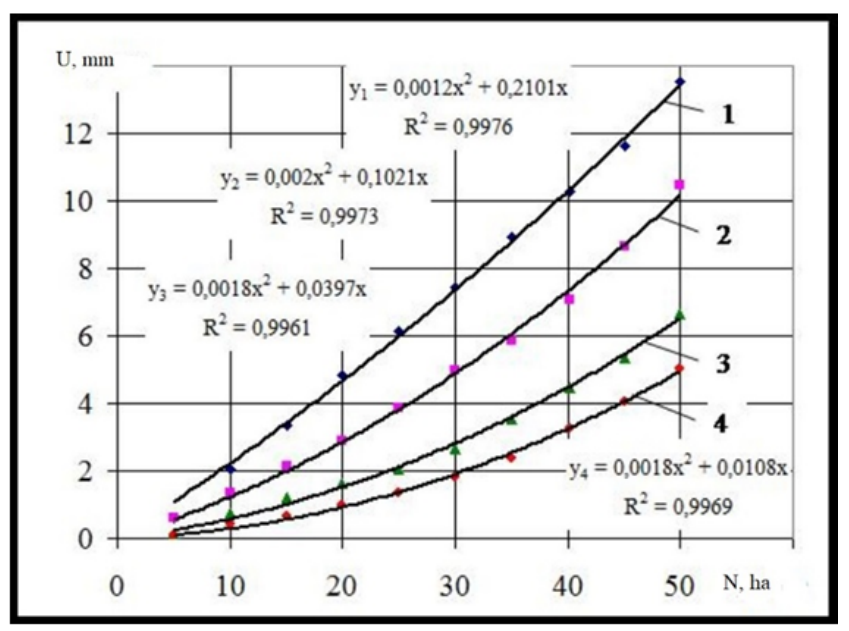

Figure 11: Dynamics of wear for experimental and serial blades caused by operating time

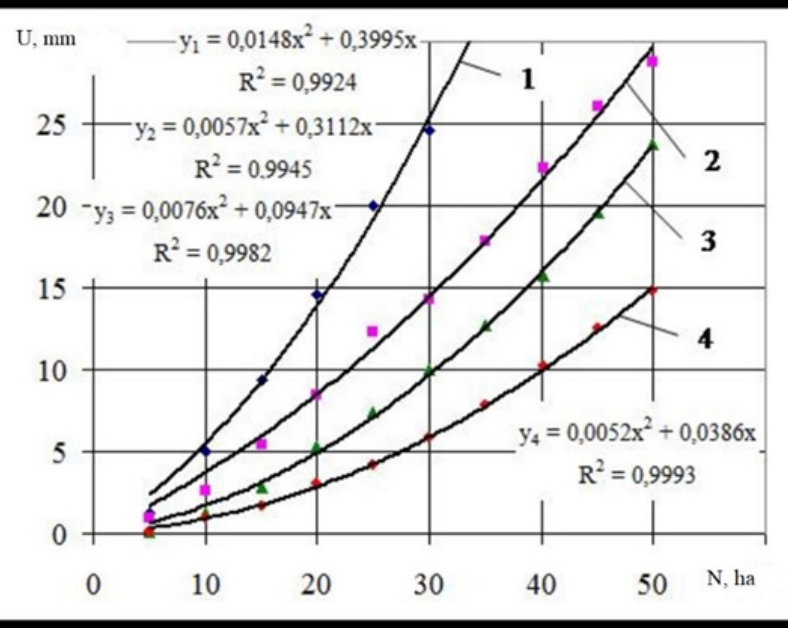

Figure 13: Dynamics of wear for experimental and serial blades caused by operating time loaded areas of the cultivator blade are the nose-piece and the blade. These parts are more prone to wear. This is also proved by the results of other researchers [16, $27,2,18,17,3,10]$. The one-sided gas-flame surfacing technology allows the application of a composite powder to worn areas (patent RU 2177392 C2), which contributes to the solution of problems [16, 18].

Experiments revealed that the worn cultivator blades cause quality violation of the cutting process. The energy intensity of the technology increase and so do the costs. This can be explained by the following design and technological parameters of the cultivator blade: the angle of nose-piece crumbling, the cone angle, and the angle of cultivator blade wings crumbling.

A comparative analysis of theoretical and experimental studies has shown that the number of cultivator blades during testing should ensure accuracy. Therefore, the normal distributive law was $0.3 . . .0 .4$., and the confidence coefficient of $a^{*}$ in the range of $0.80 \ldots 0.95$, which is considered satisfying for agricultural machinery testing [22].

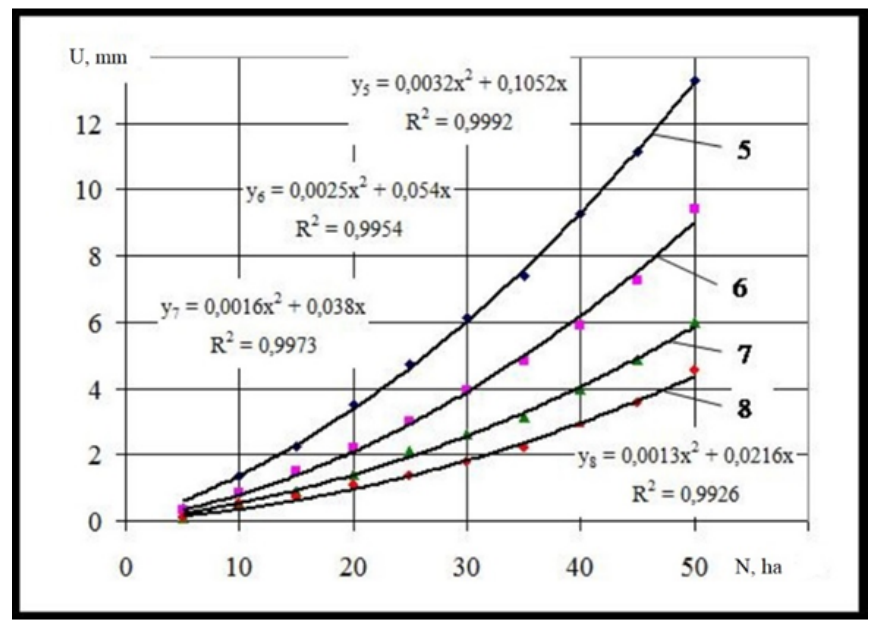

Figure 12: Dynamics of wear for experimental and serial blades caused by operating time caused by operating time

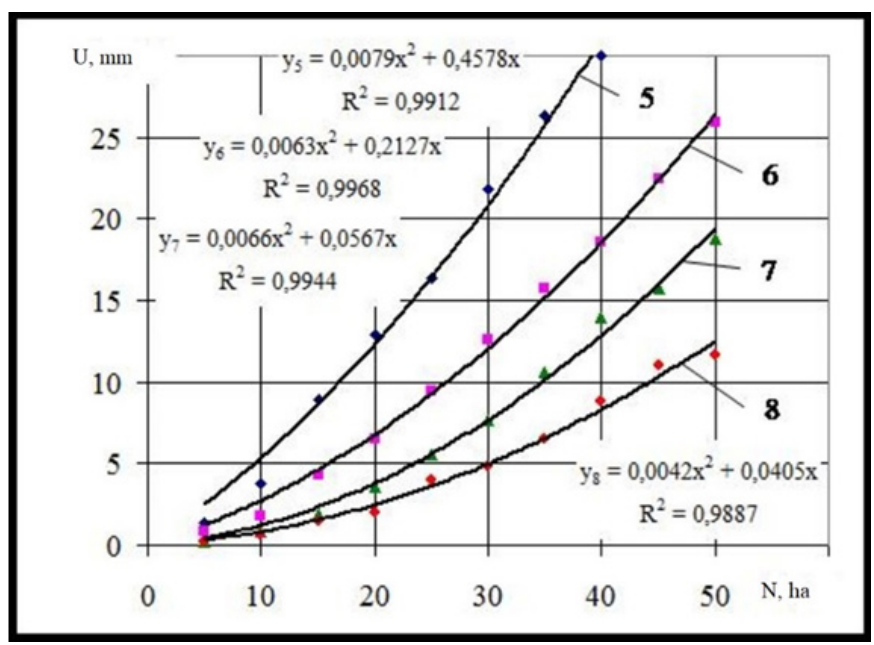

Figure 14: Dynamics of wear for experimental and serial blades caused by operating time

Istraživanja i projektovanja za privredu ISSN 1451-4117 Journal of Applied Engineering Science Vol. 19, No. 1, 2021 
Completed calculations allowed revealing optimum values of linear sizes for performing operational tests of cultivator blades which have been strengthened using the one-sided gas-flame surfacing technology. These calculations also gave the chance to diagnose agrotechnical requirements to quality of processing of soil during operation. A three-dimensional model of an existing construction of a cultivator blade, which was developed using Flow Vision software complex, made it possible to analyze the zones of greatest wear of cultivator blades during aggregation on the stages of development.

The obtained characteristics allow developing recommendations for optimizing the design and technological parameters of the cultivator blade.

The use of this technology contributes to the improvement of quality of the strengthened layer, which provides self-sharpening of the blade.

\section{CONCLUSIONS}

To sum up, the technology of one-sided gas-flame surfacing guarantees an even reinforcing layer of the cultivator blade with a width of $10-12 \mathrm{~mm}$ and a layer thickness of $0.2 \mathrm{~mm}$.

The following methods of research on the strengthened layer of the cultivator blades are given in stages:

- $\quad$ bond strength of the coating with the base metal;

- strength testing of the platforms,

- measurement of microhardness of the strengthened surface;

- $\quad$ surface roughness measurement;

- hardness measurement of the surfaced layer;

- production of microetch of cross sections of cultivator blades.

The conducted studies revealed that the microstructure of coatings obtained with the use of this technology is complex and multiphase. The pores on the scope of cover are located unevenly. In the strengthened layer of the blade, it is possible to consider the water affinity of PG-12N-02 powder and carbide grains. The boundary between the surfaced layer and the base metal is observed. The absence of pores, cracks and other defects guarantees the quality of the surfaced layer.

Operational tests of the strengthened working bodies were carried out using FFC-4 cultivator, which was aggregated on tractors of different traction classes $(1.4 ; 3 ; 4)$. At this stage, studies to assess the suitability of experimental blades to clipping of weeds have been conducted. Qualitative parameters of the cultivator blades were determined at different sharpening angles and different thickness of the blade. This technique allowed carrying out the comparative analysis of the strengthened serial and experimental cultivator blades during their operation. It also made it possible to diagnose the wear rate dynamics of the nose-piece and cultivator blade, their operating time to the limit state. All of the above allowed receiving histograms of distribution of the linear sizes of wear of cultivator blades.

\section{REFERENCES}

1. Capecchi, D. (2014). The Problem of the Motion of Bodies. Springer, Cham. doi.org/10.1007/978-3319-04840-6

2. Titov, N. V. (2012). Strengthening of working bodies of machines used in abrasive environment. Modern problems and their solutions in science, transport, production and education. International Scientific and Practical conference, pp. 46-48.

3. Feskov, S. A. (2015). Reliability of A-hoe blades of cultivators (technologies and their capabilities). Bulletin of Briansk State Agricultural Academy, vol. 1, 46-52, from https://cyberleninka.ru/article/n/ nadyozhnost-strelchatyh-kultivatornyh-lap-tehnologii-i-ih-vozmozhnosti/viewer, accessed on 202006-17.

4. Straffelini, G. (2015). Friction and Wear. Springer Tracts in Mechanical Engineering. Springer, Cham. doi.org/10.1007/978-3-319-05894-8

5. Elorz, J. A. P. S., Gonzalez, D. F., Verdeja, L. F. (2019). Structural Materials, Properties and Selection. Springer, Cham. doi.org/10.1007/978-3-03026161-0

6. Gupta, G., Satapathy, A. (2014). Studies on Erosion Behavior of Plasma Sprayed Coatings of Glass Microspheres Premixed with Al2O3 Particles. Advances in Tribology, vol. 763601, 1-11. dx.doi. org/10.1155/2014/763601

7. Fauchais, P. L., Heberlein, J. V. R., Boulos, M. I. (2014). Thermal Spray Fundamentals from Powder to Part. Springer, New York. doi. org/10.1007/978-0387-68991-3

8. Bhavar, V., Kattire, P., Patil, V., Khot, S., Gujar, K., Singh, R. (2017). Chapter 15. A review on powder bed fusion technology of metal additive manufacturing. Badiru, A.B., Valencia, V.V., Liu, D. (Eds.), Additive Manufacturing Handbook. CRC Press, Boca Raton, pp. 62-66. doi.org/10.1201/9781315119106-15

9. Panchenko, V. Ya., Vasiltsov, V. V., Ilichev, I. N., Bogdanov, A. V., Grigoryants, A. G., Makarenko, K. I., Taksants, M. V. (2017). Laser technologies of gas powder surfacing and heat treatment of drilling equipment. Photonics, vol. 7 , no. 67, 36-45. doi. org/10.22184/1993-7296.2017.67.7.36.45 
10. Gabitov, I., Saifullin, R., Farkhshatov, M., Yunusbayev, N., Pavlov, A., Gaskarov, I., Fayurshin, A., Kunafin, A., Islamov, L., Masyagutov, R. (2019). Distribution of temperature on the depth of restorable details at electrocontact welding of a steel tape. International Journal of Civil Engineering and Technology, vol. 10, no. 1, 2496-2511, from https://d1wqtxts1xzle7.cloudfront.net/58565613/IJCIET_10_01_224. pdf?1551866917=\&response-content-disposition=inline \%3B+filename\%3DIJCIET_10_01_224.pdf. pdf\&Expires $=1592388440 \&$ Signature $=L g 4 F \sim W$ GMXx-VQKzu8Is6FBUi1Cm8iyW6UnXX77ysEX5QgvzOmSsOG6Vim6XgzRrSvOrj5VIQhdUmeylnJEKxQkGyjAL hzkl6jFnexP1y13U0P6WDsGa881SkA1ckeimcn-Ss--rHfG08sTkoMFxDt2rOamfSFVJ0 Ud5qaU eyExIXMVOxaFAhYrBLUJQ9hkwi5vWmjWIFoZwgySC9HtlzVn9neclcs2F8RE2urwAogwL3mRNa4 Pbt IIPwlu7yhPub3gAc0qxrogx8 FWgHoOGo6uGM qTb6DTqE9QAOPgsc$80 \mathrm{~g} 84$ wvdke4A3y UJGeYtuiv R0qKQEItIG 50mA \&Key-Pair-Id=APKAJLOHF5GGSLRBV4ZA, accessed on 2020-06-17.

11. AlMangour, B., Yang, J. M. (2016). Improving the surface quality and mechanical properties by shot-peening of 17-4 stainless steel fabricated by additive manufacturing. Materials \& Design, vol. 15, 914-924. doi.org/10.1016/j.matdes.2016.08.037

12. Keyhany, P., Vahdat, S. E. (2016). Repair of Structural Steel Surface Groove by Using Flame Welding Method by Spraying Pure Iron Powder. Archives of Foundry Engineering, vol. 16, no. 3, 167-171. doi. org/10.1515/afe-2016-0072

13. Chernoivanov, V. I., Lialiakin, V. P., Golubev, I. G. (2016). Organization and technology of machine parts restoration. Federal State Budgetary Scientific Institution "Rosinformagrotech", Moscow.

14. Hughes, A. E., Mol, J. M. C., Zheludkevich, M. L., Buchheit, R. G. (2016). Active Protective Coatings, New-Generation Coatings for Metals. Springer Series in Materials Science. Springer, Dordrecht. doi. org/10.1007/978-94-017-7540-3

15. Srivatsan, T. S., Zhang, Yu., Harrigan, Jr., W. C. (2018). Metal-Matrix Composites Innovations, Advances and Applications. The Minerals, Metals \& Materials Series. Springer, Cham. doi.org/10.1007/9783-319-72853-7

16. Works of State Scientific Research Technological Institute. (1969). Volume 19. Scientific Research Technological Institute, Moscow.

17. Lialiakin, V. P., Solovev, S. A., Aulov, V. F. (2014). State and prospect of strengthening and restoration of tillage machine parts by welding and surfacing methods. Proceedings of State Scientific Research Technological Institute, vol. 115, 96-104, from https://elibrary.ru/item.asp?id=21817342, accessed on 2020-06-17.
18. Faiurshin, A. F., Khakimov, R. R. (2014). Special aspects of obtaining a wear-resistant coating using gas-flame hardening. Proceedings of the 5th International Scientific and Practical conference "Repair. Restoration. Renovation" 2014, pp. 235-238.

19. Song, H. Y., Evans, G. M., Babu, S. S. (2014). Effect of microstructural heterogeneities on scatter of toughness in multi-pass weld metal of C-Mn steels. Science and Technology of Welding and Joining, vol. 19, no. 5, 376-384. doi.org/10.1179/13621718 14y.0000000194

20. Shassere, B. A., Nycz, A., Noakes, M. W., Masuo, C., Sridharan, N. (2019). Correlation of Microstructure and Mechanical Properties of Metal Big Area Additive Manufacturing. Applied Sciences, vol. 9, no. 4, 787-802. doi.org/10.3390/app9040787

21. Mirhedayatian, S. M., Vahdat, S. E., Jelodar, M. J., Saen, R. F. (2013). Welding process selection for repairing nodular cast iron engine block by integrated fuzzy data envelopment analysis and TOPSIS approaches. Materials \& Design, vol. 43, 272-282. doi. org/10.1016/j.matdes.2012.07.010

22. Babu, S. S. (2018). Toward Process-Based Quality through a Fundamental Understanding of Weld Microstructural Evolution. Welding Journal, vol. 97, 1-16. doi.org/10.29391/2018.97.001

23. Duda, T. F., Raghavan, L. V. (2018). 3D metal printing technology: the need to re-invent design practice. Ai \& Society, vol. 33, no. 2, 241-252. doi.org/10.1007/ s00146-018-0809-9

24. Polivaev, O. I., Kostikov, O. M. (2016). Testing of agricultural machinery and power plants: Textbook. Lan Publisher, Saint Petersburg.

25. Burak, P. I., Pronin, V. M., Prokopenko, V. A., Mikaya, T. B., Kiselev, S. N., Zherdev, M. N., Zhidkov, G.A., Maslovsky, V.I., Koniukhov, V.V., Kolodin, L.V., Dobrynin, Yu.M, Ishkin, P.A., Pronin, V.V., Mikhailov, V.A., Beliaev, O.M., Komarov, S.A., Fedorenko, V. F. (2013). Comparative tests of agricultural machinery: scientific edition. FSBSI Rosinformagrotech, Moscow.

26. Shewmon, P. (2016). Diffusion in Solids. Springer, Cham. doi.org/10.1007/978-3-319-48206-4

27. Shilo, I. N., Betenia, G. F., Marinich, L. A., Aniskovich, G. I, Golubev, V. S., Davidovich, A. N., Drozdov, P.A., Chechetkin, A.D., Litovchik, D.I., Dekevich, I.A., Laskovnev, A.P., Ivanov, V. P. (2010). Improving the performance of parts of working bodies of agricultural machines. Belarusian State Agrarian and Technical University, Minsk.

Paper submitted: 29.07.2020.

Paper accepted: 24.09.2020.

This is an open access article distributed under the CC BY 4.0 terms and conditions. 